Paul Wells

\title{
Validating the Animated Film. Toy stories, trade tattoos and Taiwan tigers: Or what's animation ever done for us?
}

\section{Animation: a lost thing ?}

In Shaun Tan's exquisite illustrated story book and Oscar winning animated film, THE LOST THING, there is a moment when the bottle-top collecting hero of the piece, having happened upon the eponymous boiler-cum-octopus-cum-plant hybrid - the lost 'thing' - spies a small advertisement in the newspaper. The Federal Department of Odds and Ends is offering empty spaces to accommodate 'objects without names', 'troublesome artifacts of unknown origin' and 'things that just don't belong', and this becomes the eventual home of the lost thing. Even at a time when animation is everywhere from mobile phones to mainstream cinema to multi-media installations, there is still a prevailing sense that it is still something of a 'lost thing', a perennial outsider, accommodating a diversity of approaches, contexts, and achievements, but somehow still residing in Arts culture's department of odds and ends. The scope of this article then is to look again at this 'lost thing', and in a semi-polemical way, argue for the specificity, omnipresence and achievement of animation as the most enduring and significant moving image form in the contemporary era. This will take in account why animation has been marginalized, how its presence should be acknowledged in contemporary cinema, and how its specific language of expression informs highly particular works of moving image practice both in the mainstream and the independent sector.



Afbeelding 1 THE LOST THING Still from THE LOST THING. Source: http://www.thelostthing.com (trailer) http://www.shauntan.net/film/lost-thingfilm.html (trailer) 
There are, of course, any number of reasons for the lack of recognition and attention to animation as a form. Animation's confluence of all the arts idioms - painting, drawing, graphic design, illustration, sculpture, theatre, dance, musical performance etc - makes it the most inclusive of disciplines, but not one acknowledged fully in its own right. Equally, when an animated film of any sort, and about any subject, is finally celebrated it is recognized for its narrative or content, and rarely for its status as 'animation'. Ironically, this only becomes part of the debate about an animated film when the definition of just what 'animation' actually is, becomes at stake. This, for example, is at the heart of the issue in Steven Spielberg's request that his film, THE ADVENTURES OF TINTIN: THE SECRET OF THE UNICORN (2OII), be included in the Best Animated Film category in the Oscars. This provoked debate in the press, most notably, The Los Angeles Times, about the use of motion capture in this, and other films, and the refutation that Spielberg's work was animation, arguing that only traditional forms of 'frame-by-frame' animation really defined the form.

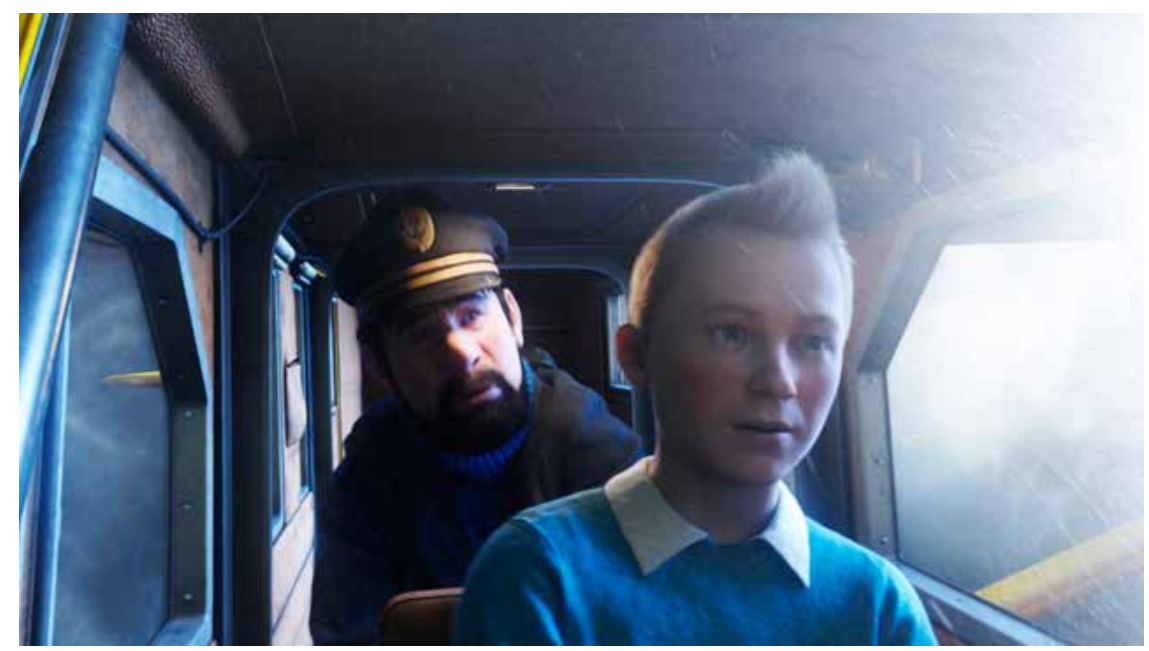

Afbeelding 2 TINTIN, wallpaper. Source:

The Adventures of TinTin, Steven Spielberg; http://www.us.movie.tintin.com (trailer)

This merely added to the debates, prompted by the claims of Andy Serkis, the actor responsible for the performances of among others, Gollum, King Kong, and Captain Haddock, that it was the actor's work that defined these characters, and not the animator's, arguing that the avatar deployed in the films was merely a digital version of costuming and make-up. Unsurprisingly, animators rejected this view, noting that a data-captured performance was just that - the capture of data - and that it was the animator that created and nuanced the performance accordingly. ${ }^{\mathrm{I}}$ There is much to address in this, since after long years of many artists and scholars championing the significance of animation, there has been some recognition that in the digital era animation is now the central aspect of contemporary cinema and not at its margins. It is also an important juncture, too, to re-assess just exactly what animation is, and what it has done for us... ${ }^{2}$ 


\section{The Animation Manifesto}

After Cholodenko ${ }^{3}$ and Manovich ${ }^{4}$, the argument now goes that such is the increased degree of 'constructed-ness' in film, using traditional film footage is merely but one part of the visual resources acquired to create moving images, and it is now the case that film practice is more akin to, or indeed, a version of animation and its craft per se. Cholodenko was the first to properly note the scandalous absence of animation in film theory, and has consistently bemoaned the marginalization of animation, particularly as a tool by which the very nature of the cinematic apparatus might be questioned or problematised. His post-structuralist critique invests animation with profound qualities that speak to aspects of philosophic enquiry into the very nature of being, of thinking, of living, but most significant here, his view that 'not only is animation a form of film but film is a form of animation'. ${ }^{5}$ Cholodenko re-formulates the 'cinematic' as the 'animatic', at once the very engine of life, motion, and essentialist presence - and its negation. Manovich's engagement with liberations and differences of new media, makes these propositions more tangible and literal, considering the operations in computer interfaces as tools by which the moving image was re-determined and re-synthesised. Manovich suggests 'Twentieth century animation became the depository for nineteenth-century moving image techniques left behind by cinema, ${ }^{6}$ only to become once more re-combined and restored in the digital era; itself revising cinema as 'digital film + live action material + painting + image processing + compositing $+2 \mathrm{D}$ computer animation $+3 \mathrm{D}$ computer animation'.7 Manovich claims, thereafter that cinema has come full circle: 'Digital cinema is a particular case of animation that uses live-action footage as one of its many elements... Born from animation, cinema pushed animation to its periphery, only in the end to become one particular case of animation'. ${ }^{8}$

All cinema then, is effectively animation. There is little chance that 'film' will be replaced by the term 'animation', however, and consequently, it constantly remains necessary to address the conditions of the form and its continuing seemingly tacit presence. Never has a form so resolutely hidden in plain sight. Over the years in which I have written about animation I have essentially spoken to this issue by creating an 'Animation Manifesto'. It is as follows :

- Animation occupies a cross-disciplinary and inter-disciplinary space between graphic design, illustration, fine-art-making, and visual practices in production and exhibition contexts.

- Animation is a versatile cross-platform medium, in feature films and TV sit-coms; cartoons and avant garde shorts; web-sites, ads and on mobile phones. This ironically, heightens its presence while diluting its profile.

- Animation has been misunderstood as a marginalised form and mainly as a children's entertainment, when in reality, it is a radical and progressive art-form and practical application.

- Animation is the only art to remain consistently and insistently experimental as it grows in mass popularity and acceptance. 
- Animation should be addressed through properly integrated methods of theory and practice, and include historical, critical and practical methodologies.

- Animation should be more acknowledged and recognised for its achievements, impact and continuing significance in the contemporary world.

While there remain many other points that might be added to this list, these have proved to be the key aspects of the debates that accrue around animation as a form. To return to my opening remarks concerning Spielberg and Serkis, the case of THE ADVENTURES OF TINTIN alone speaks to cross- and inter-disciplinary practices, multi-platform presence, a progressive engagement with quasi-canonical texts and new technologies, and further, a challenge to critical and analytical contexts in situating and appraising the film. Even leaving aside Spielberg's plea for the film to be understood as animation and Serkis' desire for more attention to be given to motion capture performance, the film recalls some of the habitual issues and problems that attend the address of animation as a moving image practice.

Speaking in an article damning the film, Nicholas Lezard, erstwhile champion of the Tintin oeuvre as one of the twentieth century's greatest works of art, goes as far as to say 'the sense of violation was so strong that it felt as though I had witnessed a rape'. ${ }^{9}$ He defends what is surely a tasteless and uncalled for remark by noting that this is what the children in South Park say when they had viewed INDIANA JONES AND THE KINGDOM OF THE CRYSTAL SKULL (2008), suggesting that the original conception of Indiana Jones as a swashbuckling adventurer was completely compromised by another sequel featuring an aged Harrison Ford. Lezard merely speaks to the irony that Indiana Jones was Spielberg's implied tribute to Tintin, and that Hergé preferred Spielberg accordingly as his Director of choice should any movie of Tintin be made. Thereafter Lezard makes a case for the veracity, attention to detail and plausibility of the Tintin narratives where 'caricature and realism superimpose themselves on each other', dismissing the 'CGI garbage of the film', 'Spielberg and his cronies' (one of whom is Peter Jackson let us not forget), and arguing this is 'Tintin for Morons', noting 'something of great subtlety, beauty and artfully deceptive complexity, resonance and depth has been betrayed, and it is time to make a stand'. ${ }^{\text {io }}$

For those of us who might have used Lezard's last remark in defence of animation over the years, his view of the film remains puzzling, since artists of the quality of Steven Spielberg and Peter Jackson - highly skilled in adapting literary works of all kinds to the screen - are not merely making blockbuster fodder nor a sop for lowest common denominator audiences. Lezard's journalistic critical perspective may seem out of place in an ostensibly 'academic' essay like this, but it is clear that Lezard's view is profoundly in the thrall of Tom McCarthy's authoritative post-structuralist reading of the Tintin stories, Tintin and the Secret of Literature. ${ }^{\text {II }}$ The book seemingly confers an intellectual authority to his piece, and is used to further critique the film - 'at least one of the screenwriters, Stephen Moffat, Edgar Wright and Joe Cornish, have read McCarthy's book (...) Alas they have not understood it'. ${ }^{12}$ Such extraordinary critical pomposity in the face of the work of such talented writers, is misplaced, since they have clearly understood the book, and have taken its chief perspectives and agencies as a method by which, not to write for film, but to write for animation. 
McCarthy essentially argues that the Tintin oeuvre "narratives are bought and sold, stolen and substituted, or twisted out of shape until, turned inside out or back to front, they mutate into other narratives ${ }^{{ }^{13} 3}$ and further that what these stories represent is 'a drama about the appearance and circulation of stories - also about their disappearance and re-emergence in another form. ${ }^{14}$ McCarthy insists that stories are inhibited or advanced through the various largely untrustworthy means by which humankind communicates, and further, stories then become embedded in objects, animals and environments, too. Spielberg and Jackson, and their writers, embrace these principles by using the mutability of animation to enable the adaptive processes by which the core action narratives of SECRET OF THE UNICORN, RED RACKHAM'S TREASURE and THE CRAB WITH THE GOLDEN CLAWS are brought together. Indeed, there is strict fidelity to the Tintin stories up to the point where any one narrative sequence is singularly best represented in comic strip form only, at which point Spielberg uses the animation to effectively and seamlessly combine stories. This works particularly well in securing a continuity in the aesthetic of each story (particularly in regard to colour palette) and is especially effective, for example, when characters embark on what David Bordwell has called 'the subjective plunge' in which the material world is surrendered to a more psychological or imaginary space. ${ }^{15}$ Haddock's alcohol and heat induced delirium in the desert in THE CRAB WITH THE GOLDEN CLAws, for example, is used as a vehicle by which to introduce the mirage of clashing sea galleons, and the back-story of Sir Francis Haddock's first encounter with his pirate adversary in RED RACKHAM'S TREASURE.

It is worth remembering, too, that Hergé himself only favoured two of his own drawings throughout all his texts. ${ }^{16}$ One from THE SECRET OF THE UNICORN features Haddock striding from a lifeboat to an island while Tintin fights off enemies, and one is from THE CRAB WITH THE GOLDEN CLAWS, where Arab gunman are poised to shoot Haddock in the desert but start to retreat in the face of his verbal abuse, expressed in text across their heads. Hergé valued the compositional values in these frames that suggested the movement of several narratives within one framed scene. Again, it is this principle that Spielberg has worked with to bring a comic book spectacle to the mise en scene. At all points Spielberg seeks to extend the mobility suggested in the original Tintin imagery, both in relation to linear sequences and embedded within singular frames. This enables him to achieve the maximum of suggestion in the minimum of imagery - a key tenet of the animated form - and use the mutability and metamorphic quality of the imagery to combine and adapt core story principles - the amalgamation of the villains in the three stories in the one figure of Sakarhin; the inclusion of the origin meeting between Tintin and Haddock; the Indiana Jones styled motorcycle chase as evidence of core character traits in Tintin and Haddock revealed through action, etc. Simply, Spielberg and his writers have demonstrated a comprehensive awareness of how animation can service and facilitate adaptation, translation and combination to speak with integrity to the original texts but also the range of viewing constituencies who want to embrace it. It is the flexibility and malleability of the animated form that enables it to readily facilitate creative responses to a range of social and cultural contexts. I now wish to address this idea in four predominant ways. 
First, its engagement with technology; second, its capacity to generate debates and discourses; third, its subsequent relationship to journalistic and documentary forms; and fourth, the fashion in which by embracing all the arts, it effectively synthesises and enhances them, potentially to sometimes negate its own distinctiveness.

\section{Post-digital animation - Animated techniques and effects}

In the contemporary era, animation may be understood in three distinct ways - traditional animation (Cartoon, Drawn, Cut-Out, Collage, 3D Puppets, 3D Clay, Experimental techniques etc); computer animation or 'digimation' (Computer applications and processes to 'affect' and 'effect' performances and environments in quasi-cartoonal form or visual effects); and as an interface with traditional 'live action' (simplistically defined here, as the photo-recording of 'theatrical' performance and real, material environments). Though feature animation is still sometimes drawn and made with $3 \mathrm{D}$ puppets, it is the independent short form that best represents the widest range of approaches and techniques in creating the illusion of movement frame-by-frame, and which is often characterised by a highly specific aesthetic created by the artist. Equally, though computer animation is predominantly defined by Pixar or Dreamworks' neo-traditionalist classical cartoon style, or by its applications in the service of photorealistic effects in mainstream movies, it may also be used to more specifically auteurist purposes, or some of its procedural aspects deployed within more traditional 'analogue' production processes.

The differentiation between the analogue and digital eras becomes specifically necessary when addressing animation as an interface with live action, since it is sometimes the case that the film-maker wishes to distinguish and differentiate between live action and animation aesthetics, while at other times making live action and animation immersive and indistinguishable. Ostensibly, the analogue era used techniques and technologies that necessarily required combining live action and animation as an optical process, often using in-camera and material effects. The digital era has enabled imagery from any source, and of sufficient quality and resolution, to be composited within the computer, and without any loss in definition. Though, in both eras, the image is entirely 'constructed', the degree of 'constructed-ness' has increased exponentially in the contemporary period because digital technologies permit wider choice, more flexibility, and greater cost effectiveness in moving image composition. It is also the case, that even though it was the intention for all animated effects to often provide the spectacle in the image, it was necessary for the effects to be so seamless and persuasive that no one would question their validity within the image, or notice their status as 'animation'. It was vital for KING KONG (I933) or the skeletons in JASON AND THE ARGONAUTS (1963), for example, to function unquestioned as key characters, even in despite of their fantasy identities and material presence as small-scale puppets. Animation in such live action vehicles had to ensure the same suspension of disbelief as the rest of the film. Looking back it is now arguably easier to see the difference between live action characters and contexts, and animated char- 
acters and effects in these kinds of films, but this is only because technologies have improved so much that such effects might be achieved with greater ease, and more fidelity to their status as plausibly real figures and forms in digitally composited films. It still remains the case that the nature and quality of the animated effect must be persuasive in the digital era, of course, and in films like HULK (2003) and VAN HELSING (2004), for all their other qualities, still include characters who fail to be believable because the effect is too excessive and the fact of their status as animation is revealed.

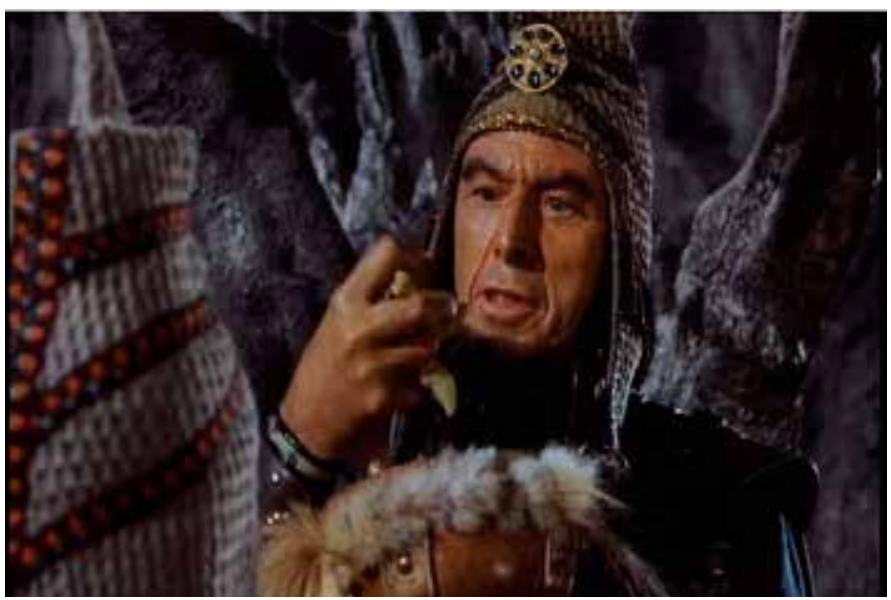

Afbeelding 3 Still from JASON AND THE ARGONAUTS (1963).

Source: http://reflectionsonfilmandtelevision.blogspot.nl/2012/01/saturday-with-sinbad-jason-and.html

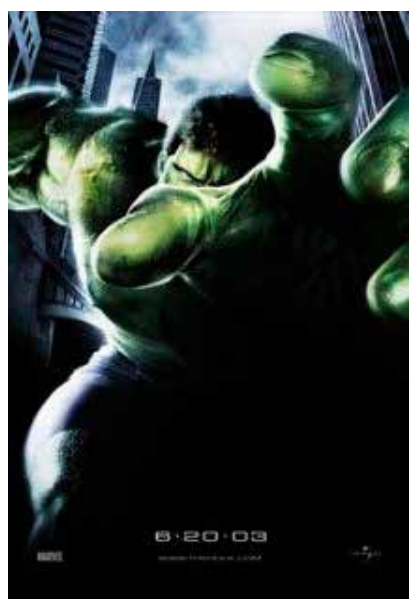

Afbeelding 4 Still from HULK (2003).

Source: $h$ ttp://www.filmtotaal.nl/foto.php?film=75562id $=6063$

Shilo McClean has identified some of the differential principles in these effects, when they are functioning in their intended way. ${ }^{17}$ In a film like CHILDREN OF MEN (2006), a verité-styled science fiction narrative, which seems on the face of it to have no animated effects, has a number of process shots, but its whole intention is to have a documentary styling that heightens the reality of its dystopic world. 
In this case the effects are invisible, and the audience must not suspect their presence. This is equally the case in films like James Cameron's TITANIC (I997) or Ridley Scott's GLADIATOR (2000), but here the animated effects are seamless because upon later consideration the audience will recognise and acknowledge the presence of animated effects as there are clearly 'impossible' shots and action that cannot be executed unless done in this way. This is especially so in period films, but also occurs in what McLean terms exaggerated form in films like THE DAY AFTER TOMORROW (2004), where an excessive, seemingly unimaginable, but 'real world' experience must be made as plausible as possible - in this case a state of global warming that creates tsunami and prompts a new ice age. I am reminded in stating this premise of Alexander Mackendrick's point that in most narrative vehicles per se the screenwriter is permitted 'one incredible thing' (ie something, in essence, implausible or plainly unbelievable), which is thereafter justified by the logical construction of the rest of the world that this 'incredible thing' is taking place within. ${ }^{18}$ Mackendrick stresses too, that when narratives are rendered in 'cartoon-like' manner all characters and environments function as the personification of ideas, and it is in this that the very specificity of animation as a form that condenses yet simultaneously intensifies visual story principles is best understood. ${ }^{19}$ In THE DAY AFTER TOMORROw, for example, the ice itself operates as a core character, but this is only achieved by treating it as such, and using photorealistic animation to create 'the incredible thing', while using the broad principles of orthodox cinematic storytelling to support its authenticity and presence.



Afbeelding 5 THE DAY AFTER TOMORROW (2004). Poster.

Source: http://en.wikipedia.org/wiki/File:The_Day_After_Tomorrow_movie.jpg

Arguably, the use of animation can enable the realisation of more than one incredible thing' in any one narrative, and this legitimises what McLean terms the fantastical in which mythic and imaginary worlds such as those in THE LORD OF THE RINGs cycle (200I-2003) are made as real as possible, and the surrealist in which self-consciously 
imagined or fantasised ideas are presented as part of an everyday sensibility or process, for example, in AMELIE (2004). The former requires that the alternative 'world' is constructed with such conviction that it seems as authentic as any material environment known to an audience, and in such a case, animated creatures like Gollum must function as plausibly as any human character in the same environ. The latter uses animation to foreground very specific visual principles, which invite their interpretation as a metaphor or a salient representation of an ephemeral interior state, which might only be rendered in non-literal terms. Both the fantastical and the surrealist play more readily on the fundamental condition of animation as a form, enabling the creation of fabricated alternative worlds that may only partially relate to a real or known one, and in the deployment of visual imagery with intrinsically symbolic, metaphoric or metaphysical purpose.



Afbeelding 6 TOY STORY, the movie poster. Source: Toy Story trilogy (1995-2009) http://en.wikipedia.org/wiki/File:Movie_poster_toy_story.jpg

After focusing on these differentiations in animated special effects McLean defines digital applications purely as the creation of 'computer animation' in its own right, citing the New Traditionalism of quasi-cartoonal, classical narratives like the TOY STORY trilogy (I995-2009), and the hyper-realism of computer generated films seeking a high verisimilitude in presenting human characters and their contexts, for example, FINAL FANTASY (200I) and BEOWULF (2007). Though both stylings use the specificity of animation in creating an alternative and particular world with its own interior logic, and employ symbolic imagery, the form is not used as self-reflexively as is normally the case in the short form. In vintage cartoons or independent auteurist approaches, it is often the case that the very identity of the animator auteur is defined by how they are self-consciously using the specificity of the form, literally defining it through their work. Chris Landreth in his film, RYAN (2004) deliberately plays with the dominant aesthetic of the new traditionalism, by presenting his subject, former animator, Ryan Larkin, as a self-consciously distressed and de-constructed figure in which his interior 
bodily form is rendered in an exterior way, and his emotional state is imagined as a set of exaggerated sinews, signs and symbols. Larkin calls this 'psycho-realism' in order to draw attention to animation's inherent capacity to penetrate such interiors, but in this case to do two further things. First, to demonstrate that computer generated imagery need not operate in a classical styling; second, that such an individual approach echoed the independent vision of his subject, Ryan Larkin, who in I969 had made WALKING, an acknowledged animation masterpiece based on walk cycles. Larkin died in 2007 after a long battle with alcoholism and mental health problems, but his place in animation history was secured by Landreth's documentary and its innovative use of computer generated imagery to create an interior rather than exterior world.



Afbeelding 7 Still from RYAN (2004).

Source: http://www.nfb.ca/film/ryan (film on-line); http://www.awn.com/articles/reviews/maya10-tureski-marks-milestones

A more orthodox but useful example of the idea of animation's core principle of self-consciously constructed alternative worlds is effects artist, Bruce Branit's wORLD BUILDER (2007). ${ }^{20} \mathrm{~A}$ man literally builds a hyper-realistic holographic world in which the computer construction of a highly detailed environment turns out to be a particular place in which he has shared an important memory with his wife. This computer generated town is built by the man, in order to instigate the same romantic memory in his wife, and to try and stimulate her subsequent recovery from a coma. Sadly, however, he fails to fully complete the environment, and this flaw, becomes the shortfall that metaphorically only confirms the artificiality of the moment, and the failure to recover the emotional import of the original experience. The illusionary world literally deconstructs. For all the man's attention to detail, particularly in the creation of a flower, nothing can be as authentic as the original experience and the feeling at its heart. Ironically, the very artificiality and illusionism of computer animation becomes 
the best vehicle by which to illustrate and reveal these emotional states. Changeux and Ricoeur could well have been speaking about wORLD BUILDER when they note,

'The connection between reflexivity and worldliness is established by bodily memory, which may itself be immediate or deferred, acted out or represented: it is a self of flesh and blood that we remember, with its moments of pleasure and suffering, its states, its actions, its feelings - which in turn are situated in an environment, and particularly in places where we have been present with others, and which we jointly remember. ${ }^{21}$

Animation has always sought to embrace new technologies to extend its vocabulary of expression, and for the animator to mediate the 'reflexivity' of the form and the 'worldliness' that it represents through the 'bodily memory' of the act of animating itself. As Sherman, therefore, stresses, 'animation is the hard copy of memory, accessed while it is being rendered by hand, or by hands assisted by machine. In general, animation is memory that moves and evolves (...) it is the concrete process of manufacturing records of psychological memory. ${ }^{22}$ The form of the expression, the act which then expresses, and the thing which is being expressed all coheres simultaneously in animation, capturing an essential and affective memory. In essence, audiences move beyond the sympathy they might experience with the external, literal characters in live action, and achieve an empathy which comes from immersing themselves in the quasi-symbolic order embodied in memory and metaphor inherent in animation. It is this capacity in animation which has led to its constant deployment in all forms of visual communication, in a variety of applications and contexts, and as the vehicle which has inspired important social and cultural discourses.

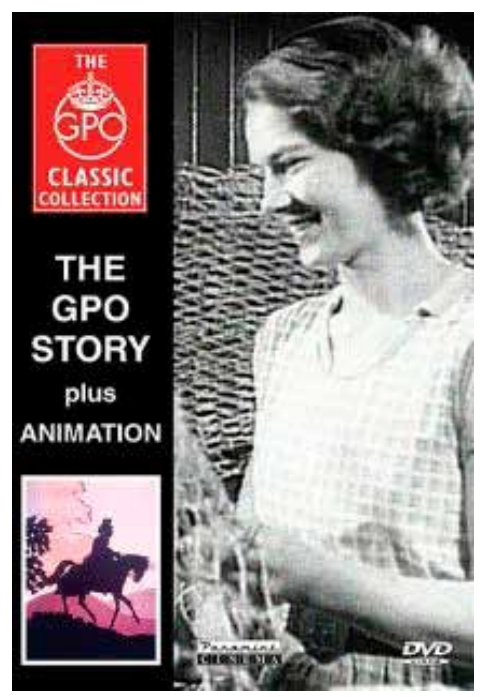

Afbeelding 8 Still from TRADE TATTOO, Len Lye (1937).

Source: http://ukanimation.blogspot.nl/2011/01/trade-tattoo-by-len-lye.html 
Interestingly, though this might be most obviously evidenced through the use of animation in public information films, propaganda, industrial films, music videos, advertising or documentaries ${ }^{23}$ it is useful to look at an example which essentially combines all of these within an important moment of social engagement and mobility, and yet also facilitates specific authorial identity and experimental art-making. Len Lye's TRADE TATTOO (I937), influenced by Walter Ruttmann's BERLIN: A CITY SYMPHONY (1927), is essentially about working life in Britain in the mid-I930s, and incorporates live action footage cut from John Grierson's GPO documentaries, featuring steel works, loading, and mail sorting. This is mixed with, and overlaid by layers of bright Technicolor images, rhythmically animated to imitate the patterns of a festival style display - a tattoo. At one level, an abstract film, but at another, simply a commercial commissioned by the GPO (subdivision of the UK General Post Office) to encourage people to post their letters early to ensure arrival on time, and to support the theme that British trade is facilitated by the work of the Post Office. It is clear though that Lye's syncopated, radiant, highly affecting film is informed by a romanticism that serves to re-imagine the social democratic, realist principle defining Grierson's documentary outlook. Animation here effectively and seamlessly combines contrasting aesthetics and multiple themes, and seemingly transcends populist genres while still speaking to mainstream audiences. Grierson saw the work of the GPO Film Unit as a series of socially-orientated 'publications' arguing for, and revealing the importance of democratic practice. Sponsoring 'art' films, like Lye's and adding a commercial principle, deliberately sought to show literally that the 'freedom of expression' was at the heart of the social agenda, part of a political economy, and best epitomised in animated form. ${ }^{24}$

\section{A matter of life and death - art, animation, cartoon}

It remains curious that even in the face of such evidence, and the achievements of artists like Len Lye and Norman McLaren, and numerous Fine Artists working in animation ever since, that there still remains a doubt about whether animation should be recognised as 'art', and further, that there is long resistance to the notion that there is a genre of 'animated documentary', even though there is over a hundred years worth of evidence about animation's engagement with non-fiction. A recent exhibition - 'Watch Me Move - The Animation Show ${ }^{25}$ sought to re-dress the schism between art and animation by placing animated moving images in the gallery space. Though this has been done on many occasions before, though on a smaller scale most notably by the enlightened curatorial stance at the Museum of Modern Art in New York ${ }^{26}$ - it both identified the prejudices of arts culture in accepting animation as a bonafide art form, and readily evidenced the aesthetic achievements of animation in a variety of idioms, historical periods and national cultures. Though many artists use animation in their work, there is great resistance to the idea that they should be called 'animators' because for many, this aligns them with the animation industry, and modes of entertainment, not art. ${ }^{27}$ In such cases, animation is merely but one 
tool or application for an artist, and not a defining agency in their professional identity. William Kentridge, for example, has long produced animated films, famously 'stalking the drawing', ${ }^{28}$ but resists being aligned with the animation community. Tracey Emin, the renowned British artist, in focusing more on drawing in a recent exhibition - 'For Those Who Suffer Love' (2009) - also included animation, but again saw this as merely an extension of her expression through drawing, and not something which aligned itself with any particular approach to drawing for animation. ${ }^{29}$ Indeed, a whole exhibition was mounted at Parasol Unit in London - 'Momentary Momentum' (2007) - bringing together a range of such moving image works - animated films - but made by 'artists'. While there was some undeniably high quality work, there remained the frustration - for me, at least - that little of the work would be acknowledged as high quality if contextualised within the field of art or classical animation. This approach was legitimised by naming the work within an artist's canon, and as incumbent of the gallery space, rather than by any reference to the field it actually speaks more closely to. What this means is that arguably inferior works of observation, humour and technical application are rewarded higher status than those works consistently marginalised by their definition as animation, or their equally limited acknowledgment by mainstream cinema and film culture.

What this has the consequence of doing, however, is to prompt debates within the field of animation about the status of the work. In his now fondly remembered polemic, the late Dick Arnall, for example, suggested,

'I believe it's time to kill animation. Not the animation we watch, but the word we use to label it. Everyone out there knows that animation means 'invented' characters brought to life on the screen by an animator. But those of us inside the world of the moving image, also use the term 'animation' to refer to just about anything that isn't direct live-action, created by just about any alternative means for just about any aesthetic, narrative or conceptual reason. We lump together all these techniques, forms and ambitions, call them animation and, frankly, to say the least, it's just not helpful (...) Let's return to 'cartoon' to describe regular character-based storytelling, whether it's THE SIMPSONS, WALLACE \& GROMIT or TOY STORY. Death to 'animation'. It's time to find a new word for "the extended moving image". '30

While Arnall was clearly trying to intervene in debates about the defining principles of animation, there was an implied hierarchical interest here that sought once more to separate 'art' animation from its more populist counterparts, and in doing so, advance terminology that supposedly better represented the new independent animated cinema of the digital era. There is something perverse in this, though, since no one would abandon the word 'film' because it was too generic, nor abandon it because moving image practice has increasingly turned to digital methods and applications. 'Animation' and 'cartoon' are terms with rich tradition and longevity, and all aspects of 
differentiation between work needs to be made on a case by case basis. 'The extended moving image', for example, as a term is no more precise than 'animation', as it would still include every application in animation from cartoons to special effects. Some of this thinking inevitably comes about to service the claims of 'theory', which in Animation Studies has moved from a largely defensive position fiercely arguing for the recognition and specificity of the form ${ }^{31}$ through to a broad church of critically sophisticated readings, which fundamentally place animation at the centre of Film and Cinema debates, and increasingly, not only as an engagement with its own techniques and achievements, but as a vehicle by which to fully address the social world, and prompt discourses within it.

While it has never been the case that animation hasn't taken the world seriously, there is little doubt this has been obscured by the view that cartoon, and animation in general, is somehow inherently 'funny'. Self-evidently, the prominence and reach of the American animated cartoon is largely responsible for this, but with the greater impact of animation in the contemporary era, and the opportunity to see much more animation from all over the world on the internet, and in Festival retrospectives of previously unseen work, the very historiography and perception of animation is changing. This has been enabled further by the ways in which major animated features have taken up serious themes, and seemingly more niche animated features have achieved a certain mainstream crossover, and crucially, prompted public debates. For example, Pixar Animation created almost dystopian worlds in films like WALL-E (2009), with its vision of environmental and consumerist apocalypse, or UP (2009), with its depiction of alienated and embittered senior citizens still seeking to find a valid foothold in an increasingly indifferent world. Even in TOY STORY 3 (20I0), the toys face extinction in almost Dante-esque style, and profound issues of relationship, purpose, loss and grief are explored unflinchingly for what would be nominally regarded as a mainstream family entertainment. The upshot of all of this were four key social discourses. First, the film's market position, in which it topped the global Box office takings list. Second, the film's status within cinema prompting speculation whether this along with TOY STORY (I995) and TOY STORY 2 (200I) constituted the greatest film trilogy ever, challenging such stalwarts as THE GODFATHER, LORD OF THE RINGS and BACK TO THE FUTURE. Third, the reception of the film, which essentially concentrated on the capacity for the film to make male adults cry, and fourth, the impact of the film, in apparently encouraging children to so value their toys that parents were now struggling to find acceptable strategies by which their children would permit them to be thrown away or passed on in some way. 




Afbeelding 9 The UP poster (2010).

Source: http://en.wikipedia.org/wiki/File:Up_Poster.JPG

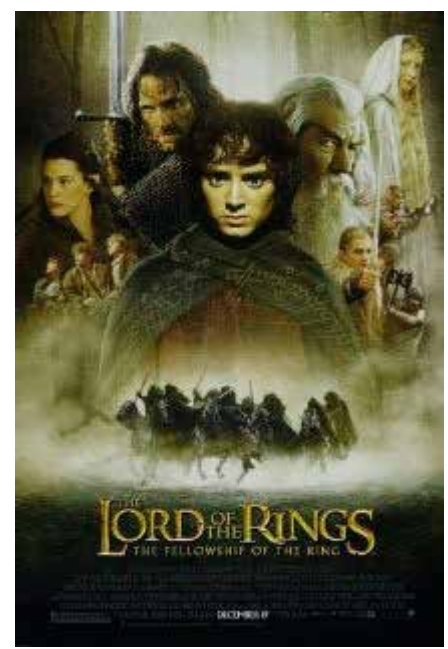

Afbeelding 10 Still from Gollum in THE LORD OF THE RINGS.

Source: The Lord of the Rings cyle (2001-2003); http://www.awn.com/imagepicker/image/15018

These four agendas - market presence, standing as and within cinema, reception and impact - are equally useful measures for crossover works like PERSEPOLIS (2007) and WALTZ WITH BASHIR (2008). Both were comparatively successful at the box office; both generated key debates about how animated film could be used to mediate and represent historical sources and re-define 'documentary'; both enjoyed significant critical reception and given their subject matter prompted re-engagement with the political scenarios in Iran and the sustained tensions between Israel and Palestine; finally, both prompted major exchanges at all social levels on-line and through social networking. These new models of reception and social engagement also informed the response to Ali Samadi Ahadi's the GREen WAVE (2OIO), which represented Iran's 
'Green Revolution' through first person materials recorded on mobile phone cameras, blogged and tweeted on line, witness interviews, and most notably, through animation dramatizing the unseen atrocities of the government militia brutalizing dissenters in dispute with the outcome of the 2009 election. Amid suspicions of vote rigging and corruption when conservative Mahmoud Ahmad was unexpectedly returned to office, protesters stood out against the apparent abuse of a hard fought for democratic process. Though the film itself was made in Germany, its presence both in and outside Iran was profound. Iranians outside Iran could sustain and maintain their own more informed dialogue, while those within could see on-line extracts or bootleg copies of the documentary as a 'witness' to events and a significant provocateur for increased activism..$^{32}$ These latter works have proven the importance of using animation as a language of democratic expression, but perhaps more importantly, as a mode of documentary working with the agencies of memory and visualization. Crucially, animation is permitting stories to be told that would otherwise have no vehicle for their expression. This, of course, is at the heart of some resistance to the concept of 'animated documentary' by more orthodox documentary film-makers and scholars. ${ }^{33}$

One approach to this may be to draw upon the work of Nick Kaye, when he talks about the documentation of site-specific art-works. In essence, these function as both the research for, and recorded outcomes of, a creative process and outcome, which are not occurring in real time, nor in the gallery space. The documentation, therefore, acts as evidence for the process and final work in its absence. As Kaye points out though, 'Documents do not simply reflect upon the apparent contradiction of attempting to record site-specific works in another place, time, and through another medium, but act out some of the complexities of the relationship between work and site' ${ }^{34}$ This is a crucial aspect of the animated documentary in that it functions as a discourse between its subject and sources and the illusionism of its essayistic interpretation of the material. Crucially, the animated documentary, as such, foregrounds the subjectivity, authorship and constructedness of the documentary form, challenging its long sustained mythologies of actuality film-as-truth, and generic tropes as codes of 'objectivity'. As Kaye remarks again, 'One of the first observations one might make of these documentations is their sensitivity to their own limits, their willingness to concede the impossibility of reproducing the object'. ${ }^{35}$ Animation fundamentally acknowledges these limits in the self-conscious re-engagement and re-imagining of source materials, and thus invites critical commentary, public discourse, and key investments in both the interpretation and interrogation of received and perceived 'realities'. Animation, as is clear from the nature of its language of expression in all forms, always has a different relationship to the 'object', always taking into account its mobility, changing status, and propensity to change. In working with, and often producing this 'flux' as its subject animation always echoes and reflects the very things it records, bringing to them what Kaye calls, in relation to site-specific art which is not present, a 'perceptual exposure'. Animated documentary offers this very same 'perceptual exposure' in operating as a 'non-site' to the site-specific nature of its topics, pre-occupations, and issues. It offers an 'exposure' to material that has gone through 
a 'perceptual' filter, and which therefore encourages a response to the discourse raised, rather than passive acceptance of the authorial aesthetic or argument. It is this that once again both proves and evidences the distinctiveness of animation, but also vividly illustrates its critical challenges and problems.

\section{The inclusive art - the cross/inter/multi-disciplinary form}

Animation's capacity to embrace all of the other arts within its production process, as I have argued, on the one hand, hides its virtuosity and identity as a form, while on the other, liberates it to be used as a radical tool in the re-invention or re-engagement or re-interpretation of social, cultural and historical materials. This has led to an exponential rise in the production of 'animated documentary' and the use of animation in news and documentary contexts, as well as continued experimentation in narrative form. In many senses, it is this versatility that undermines any notion that animation as any indexical certainty, and as a result leaves it open to the view that it lacks 'authenticity' when engaging with non-fictional issues and contexts. This is an area of considerable debate especially when companies like Next Media Animation from Taiwan, create animated versions of news stories that they do not have footage for - Tiger Woods disagreement with his now ex-wife; Prince William proposing to Kate Middleton, and the subsequent engagement party; or Elton John and his partner, David Furnish, at the moment when they adopted their baby. The company is clearly working in the tradition of the editorial cartoon in which an implied satirical perspective is being offered as part of the news agenda. The viral success of these pieces, though, moves them beyond the immediacy of the moment of reportage, and into the public domain as animated vignettes, highly revealing about cultural difference. Crucially, too, they celebrate and advance a tabloid news agenda which gains a great deal of populist global currency.

Woods' narrative, for example, features his ex-wife, Erin, following his car, hammering it with a golf club, until he crashes the car into a tree. Prince William falls in love with Kate Middleton as she seeks to help him recover after he has been sick in a University toilet. Middleton's status as a 'commoner' is read as an excuse for depicting an engagement party in a working class pub, and the Duke of Edinburgh pinching ladies' bottoms. The England Rugby team is also taken to task with animated footage of the now notorious 'dwarf-throwing' party. Post Woods every major sex scandal is given the Next Media treatment, with tabloid allegations now 'evidenced' in imagined animated sequences. The animation is of low quality; the incidents themselves playfully, and sometimes wittily handled; yet despite the self-evident artifice in the production there is an assumed veracity in the representation. At one level, then, something which might be seen to misrepresent but on the other, implicit evidence of animation as a radical language of expression, clearly working beyond the limits and orthodoxies of conventional news coverage, and indeed, the ideologically determined limitations of dominant corporate cultures. 
This radical language works powerfully in other applications. Samantha Moore's realization of the condition of synaethesia in AN EYEFUL OF SOUND (2OIO) $)^{36}$ visualizes the neurological projections of people involuntarily imagining certain sounds and linguistic signs as colours, personifications, etc, with highly perceived affect and memorability. The apparent illogicality and visual incongruities of such an interior state find ready purchase in animation, however, as such states of consciousness are informed by the very liminality and flux that informs non-objective, non-linear forms of experimental animation. As William Moritz has stressed,

\begin{abstract}
'Non-objective animation is without a doubt the purest and most difficult form of animation. Anyone can learn to 'muybridge' the illusion of representational life, but inventing interesting forms, shapes and colors, creating new, imaginative and expressive motions - "the absolute creation, the true creation" as (Oskar) Fischinger termed it - requires the highest mental and spiritual faculties, as well as the most sensitive talents of hand' ${ }^{37}$
\end{abstract}

While I do not share Moritz pejorative dismissal of character animation, it is clear that at one level this model of abstract visual invention is indeed, an important imaginative act, but as Moore's work proves, animation can literally be 'the concrete process of manufacturing records of psychological memory' suggested by Sherman ${ }^{38}$ and the animator, the mediator of a radical language that can service both images of perception and reception simultaneously. The external world can be rendered literally, metaphorically and symbolically, but essentially, in animation all representation is abstract, filtered through the self-reflexive filter of the animator's empathy. We should be clear, then, that this is not just the mental, spiritual and sensitive talent of an experimental film-maker and artist like Oskar Fischinger, but also, the great cartoon directors, like Tex Avery, who Chuck Jones once described as one of the world's greatest 'abstract' film-makers because he best exploited the inherent abstraction of animated characters and environments, and that this should be properly recognized as the art of animation. ${ }^{39}$

Animation, then, remains an inclusive art, made by an inclusive community. One might immediately re-write that sentence as animation remains an exclusive art made by an exclusive community. In either case, it acknowledges that on the one hand the field can include works by film-makers like Igor Kovalyov, or Priit Parn, the latter of whom insists that simply by engaging in animation one thinks differently, and such an approach asks the audience to read his films as if reading a book; while on the other, can accommodate visual stylists like Nathalie Djurberg, PEs, semiconductor or Julian Opie, all of whom re-invent models of animation by re-imagining people, objects, material environments, and motion itself, as fresh, newly abstracted encounters. Equally, it is a field that can embrace the ironic, rotoscoped narratives of Dennis Tupicoff, the nostalgic story-telling of Nick Park, and the sustained visual playfulness of Joanna Priestley, all of whom may be viewed as film-makers contributing to the idea of animation as the embodiment of contemporary myth, folktale and legend. All 
such work emerges from long standing traditions in applied techniques, genres, and national cultures; traditions which have emerged much more transparently through the scholarship and research in animation in the last thirty years. The richness, diversity and complexity of the form is being increasingly recognized, but this merely reinforces the view that there is still much to be discovered and excavated, understood and promoted. Archive holdings, and as yet unknown collections of animated film, past, present and future, will necessarily be discovered and throw further light on a form that is fundamentally about time itself. As Ülo Pikkov as astutely noted:

'Time is the most important agent of the animated film, its invisible protagonist. The animated film provides an opportunity to manipulate time, but under no condition can time be ignored. This leads to a perplexing magic, which gives life to inanimate characters and convinces viewers of the spirituality of things. Achieving harmony between internal and external time is true evidence of artistic mastery in animated film'. ${ }^{\circ}$

Animation's perplexing magic has ensured that moving image practice has been physical and metaphysical; material and immaterial; linear and non-linear; lasting one second or a million years; one long abstraction that reveals the human condition in distinctive and insightful ways. When anyone asks me, 'What's animation ever done for us?', I answer, 'Isn't that enough?'...

\section{Notes}

I See: Paul Wells, 'Where the Rubber Hits the Road: The Illusion of Animation' in: Animation Practice Process and Production, Vol. I, No. 2, Sept. 2012, pp. I97-207.

2 In Monty Python's LifE of BRIAN (Dir: Terry Jones, UK, I979), the rebellious People's Front of Judea discuss their proposed overthrow of Roman rule. After an increasingly ironic discussion, Reg, their leader is forced to ask, 'All right. But apart from the sanitation, the medicine, education, wine, public order, irrigation, roads, the fresh water system, and public health... What have the Romans ever done for us?' My reference to this much cited speech, picks up the irony of the constant dismissal of animation in the face of its richly evidencible and obvious presence, distinctiveness and success. The overall discussion, therefore, speaks to scholars, artists, administrators, funders and even the general public in encouraging proper acknowledgement and understanding of the form's distinctiveness and achievements.

3 Alan Cholodenko, The Illusion of Life: Essays on Animation, Power Publications in Association with the Australian Film Commission, Sydney I99I; Alan Cholodenko, The Illusion of Life 2: More Essays on Animation, Power Publications, Sydney N.S.W, Australia 2007.

4 Lev. Manovich, The Language of New Media, MIT, Cambridge MA 200 I.

5 Cholodenko, The Illusion of Life, p. 22.

6 Manovich, The Language of New Media, p. 298.

7 Manovich, The Language of New Media, p. 30I.

8 Manovich, The Language of New Media, p. 302.

9 Nicholas Lezard, 'How Could They Do This To Tintin?’, The Guardian, G2, I9/ıо/20II, pp. 6-го.

Io Lezard, 'How Could They Do This To Tintin?'

II Tom McCarthy, Tintin and the Secret of Literature, Granta, London 2006.

I2 Lezard, 'How Could They Do This To Tintin?' 
I3 McCarthy, Tintin and the Secret of Literature, p. I5.

I4 McCarthy, Tintin and the Secret of Literature, p. I6.

I5 Bordwell used this term when speaking at the international Screenwriting Network Conference in September 20 II.

i6 See Tintin Et Moi (Dir: Anders Ostergard, Den/Bel/Fra/Swit/Swe/USA, 2003).

I7 See: Shilo T. McClean, Digital Storytelling: The Narrative Power of Visual Effects in Film, MIT, Cambridge MA 2007.

I8 Alexander Mackendrick \& Paul Cronin, On Film-making: An Introduction to the Craft of the Director, Faber and Faber, London 2004, p. II4.

I9 Mackendrick \& Cronin, On Film-making, p. 87-89.

20 http://www.youtube.com/watch?v=VzFpg27Ism8

2I Harriet Harvey Wood \& A.S. Byatt (eds), Memory: An Anthology, Chatto \& Windus, London 2008 , p. I85.

22 Chris Gehman \& Steve Reinke (eds), The Sharpest Point: Animation at the End of Cinema, YYZ /Ottawa International Animation Festival/Images Festival, Toronto on 2005, p. I94-I95.

23 See: Vinzenz Hediger \& Patrick Vonderau, Films That Work: Industrial Film and the Productivity of Media, Amsterdam UP, Amsterdam 2009.

24 This point was gleaned from a BBC interview conducted by the author with Norman McLaren in the early i980s.

25 See: Greg Hilty \& Alona Pardo, Watch Me Move: The Animation Show, Barbican, London 20 II.

26 MOMA has staged exhibitions by among others, Pixar Animation, and Tim Burton.

27 See: Benjamin Cook \& Gary Thomas, The Animate! Book: Rethinking Animation, LUX, London 2006.

28 See: Gehman \& Reinke, The Sharpest Point, p. 96-I25.

29 See: Paul Wells \& Joanna Quinn, Drawing for Animation, AVA Academia, Lausanne 2009.

30 Adam Pugh (ed), $4^{\text {th }}$ Norwich International Animation Festival Catalogue, 2005, p. 88-89.

3I See: Norman M. Klein, Seven Minutes: The Life and Death of the American Animated Cartoon, Verso, London I993; Paul Wells, Understanding Animation, Routledge, London I998; Paul Wells \& Johnny Hardstaff, Re-imagining Animation: The Changing Face of the Moving Image, AVA Academia, Lausanne 2008; Maureen Furniss, The Animation Bible: A Practical Guide to the Art of Animating, from Flipbooks to Flash, Abrams, New York 2008; Andrew Selby, Animation in Process, Laurence King, London 2009.

32 Personal Interview with the Author June 2 огі.

33 At the International Documentary Film Festival in Amsterdam in 2007, a panel session and programmes of animated documentaries were shown for the first time, prompting formal and informal debate about their status as authentic documentaries. Many film-makers and spectators believed that they did not function as documentaries, and at best, were personal essay films. See Animation: An Interdisciplinary Journal, Vol. 6 No 3, Nov. 20II: 'Making it (un)Real: Contemporary Theories and Practices in Documentary Animation. [Guest Editor: Jeffrey Skoller]

34 Nick Kaye, Site-specific Art: Performance, Place, and Documentation, Routledge, London 2000, p. 2I5216.

35 Kaye, Site-specific Art, p. 215.

$36 \mathrm{http}: / /$ www.youtube.com/watch?v=BnZLjMT6m3g of http://eyefulofsound.blogspot.nl/20I2/o8/

an-eyeful-of-sound-is-now-online.html (film on-line)

37 John Canemaker, Storytelling in Animation: An Anthology, American Film Institute, Los Angeles CA I988, p. 25 .

38 See: Gehman \& Reinke, The Sharpest Point, p. I95.

39 Personal Interview with the author, Sept 1997.

40 Ülo Pikkov, Animasophy. Theoretical writings on the animated film, Estonian Academy of Arts 20IO, p. 53. [http://artun.academia.edu/ÜloPikkov/Books/II84792/Animasophy._Theoretical_writings_on_the_ animated_film] 